VI Congresso Brasileiro de Informática na Educação (CBIE 2017)

Anais do XXVIII Simpósio Brasileiro de Informática na Educação (SBIE 2017)

\title{
Identificação e Adaptação do Nível de Habilidade em Jogos Educacionais
}

\author{
Gabriel R. Silva ${ }^{1}$, Elaine H. T. Oliveira ${ }^{1}$, José Luiz S. Pio ${ }^{1}$ \\ ${ }^{1}$ Instituto de Computação, Universidade Federal do Amazonas, Manaus, Brazil \\ gabrielreisesilva@gmail.com, \{elaine,josepio\}@icomp.ufam.edu.br
}

Resumo. A denominação jogos sérios ou jogos educacionais refere-se àqueles criados com o objetivo de ensinar e aprender. Um desafio recorrente no desenvolvimento desses jogos é balancear o aprendizado e a diversão. Dentre as abordagens desenvolvidas para tratar este problema, está a adaptação com o auxílio de técnicas de aprendizagem de máquina. Este artigo apresenta a criação de um método baseado nos padrões de design de jogos educacionais e no modelo ARCS de motivação, somado à adaptação de uma rede neural artificial a fim de balancear a dificuldade do jogo. Descreve-se ainda o desenvolvimento de um jogo educacional segundo o método proposto. $O$ aplicativo foi validado por alunos do curso de Engenharia da Computação da Universidade Federal do Amazonas.

Abstract. Serious games, or educational games, refer to games used for the purpose of teaching. A challenge for those games is to balance between teaching and having fun. Several approaches were developed to resolve this issue, and one of them is adaptation using machine learning techniques. This article presents the development of a method based on educational game design patterns and ARCS motivational model, in addiction with an artificial neural network aiming to balance the game. Also, it describes the development of an educational game following the proposed method. The app was validated by undergraduate students of Computer Engineering of Federal University of Amazonas.

\section{Introdução}

Jogos são criados com o intuito de entreter e divertir pessoas, mas sua metodologia pode ser usada para muito mais que isso. Todo jogo necessita de regras e um objetivo, e essas regras podem ser adaptadas para fornecer uma ferramenta única que complementa as técnicas de ensino tradicionais, proporcionando diversidade e criatividade em novas estratégias de ensino. Segundo Erhel e Jamet (2013), esses jogos são feitos para promover o conhecimento ou o desenvolvimento de habilidades cognitivas, permitindo aos estudantes que pratiquem suas habilidades em um ambiente virtual. Com efeito, ao jogar é possível aprender e 
VI Congresso Brasileiro de Informática na Educação (CBIE 2017)

Anais do XXVIII Simpósio Brasileiro de Informática na Educação (SBIE 2017)

solucionar problemas. Além disso, alguns jogos são capazes de motivar e engajar de uma maneira tal que não é comum na maioria das técnicas de ensino.

O nível de interesse do estudante em aprender pode afetar sua vida acadêmica. Sabese também que isto é um problema que vai além da mentalidade do estudante, é também um reflexo de técnicas de ensino que não direcionam todo o potencial de aprendizagem do aluno. Seguindo esta linha de raciocínio, Kim et al. (2009) diz que "jogos digitais têm potencial como um ambiente de aprendizagem por serem uma forma de lazer que motiva estudantes através do entretenimento".

Serious games se refere a jogos usados para treinamento, propaganda, simulação, ou educação que também possuem a experiência desafiadora de um jogo [Susi et al. 2007]. Mesmo com a intenção de entreter alunos enquanto aprendem, vários serious games não cumprem sua missão, na medida em que sacrificam a jogabilidade e focam apenas no conteúdo a ser ensinado, tornando o jogo tedioso [Pogačnik 2009] e sacrificando o interesse do aluno em aprender sobre o assunto abordado. Considerando isso, várias pesquisas já foram realizadas sobre o nível de interesse dos alunos ao jogar serious games e sua influência no aprendizado [Bouvier et al. 2014; Baker et al. 2010; Jovanovic et al. 2011]. Segundo Bouvier e colegas, a falta de interesse ao jogar esses jogos é inversamente proporcional ao aprendizado do aluno e é um problema que deve ser solucionado.

Diante desse contexto, este trabalho busca uma maneira de tornar jogos educacionais mais interessantes tanto para aqueles alunos com mais experiência em jogos quanto para aqueles que jogam apenas ocasionalmente, ou não jogam. Identificando-se as habilidades dos jogadores e unindo estas informações a um jogo educativo, é possível motivar os estudantes a continuarem interessados e aprendendo cada vez mais. O trabalho se baseia na hipótese de que uma rede neural artificial (RNA) pode ser utilizada para a identificação das habilidades do jogador a partir do desempenho deste nas atividades presentes no jogo.

O objetivo do presente artigo é apresentar uma ferramenta para identificação do nível de habilidade de jogador do aluno de maneira transparente a ele e realizar a adaptação da dificuldade do jogo de acordo com esse nível. Esta adaptação é feita de maneira que a gameplay do jogo é ajustada de acordo com o modelo ARCS (Attention, Relevance, Confidence, e Satisfaction) de motivação [Keller 1987] e estruturada de acordo com os padrões de design para jogos educacionais [Kelle 2011].

\section{Trabalhos relacionados}

O objetivo de um jogo educacional é ensinar o jogador enquanto este se diverte. Para isso, é necessário deixá-lo interessado e motivado a jogar. Estudos já mostram que jogos podem ser usados como ferramentas efetivas para ensinar [Ke e Grabowski 2007], mas é necessário que 
VI Congresso Brasileiro de Informática na Educação (CBIE 2017)

Anais do XXVIII Simpósio Brasileiro de Informática na Educação (SBIE 2017)

o jogo consiga manter o aluno interessado e motivado para que possa cumprir seu objetivo [Bouvier et al. 2014].

Chun et al. (2015) desenvolveram um método para fazer o ajuste de dificuldade em jogos educacionais móveis. Para o método proposto, era necessário que o aluno respondesse um questionário ao fim de cada exercício, para então processar-se a dificuldade do próximo. Porém, Hunicke (2005) afirma que "para o ajuste ser efetivo, é necessário que seja feito sem interromper ou atrapalhar a experiência principal do jogo", caso contrário o jogador pode se sentir "traído" e, consequentemente, desmotivado a continuar jogar.

Peirce et al. (2008) propuseram uma arquitetura focada na adaptação sem comprometer a jogabilidade. Esta consistia em dividir o mecanismo de adaptação em quatro partes: (i) inferência, no qual são lidos os movimentos do jogador e processados em uma rede neural; (ii) adaptação, segundo a qual, com a habilidade identificada, o sistema determinava qual adaptação poderia ajudar a treiná-la; (iii) execução, etapa na qual se definia o melhor momento para a adaptação ocorrer no jogo; e (iv) game engine, em que as adaptações eram realizadas, dentro do jogo, evitando ser evidenciada pelo jogador de uma maneira brusca. Apesar da eficácia da arquitetura, sua execução demanda um processamento custoso e contínuo, sendo inviável para plataformas móveis, onde o maior problema é a bateria limitada.

Wong et al. (2006) desenvolveram dois sistemas diferentes para ajustes de dificuldade usando redes neurais. O primeiro sistema, integrado ao jogo, permitia ao usuário escolher previamente a dificuldade que gostaria. $\mathrm{O}$ segundo design permitia uma adaptação dinâmica da dificuldade, respondendo a eventos do jogo e ajustando a dificuldade de acordo. Ao ler certos parâmetros de desempenho, o sistema identificava a dificuldade mais apropriada e carregava os valores dos nós para esta dificuldade. Porém, esta troca de valores veio a ser algo custoso ao jogo, muitas vezes causando uma perda de desempenho e interrompendo o fluxo do jogo.

\section{Metodologia}

A abordagem metodológica é desenvolvida em cinco etapas. Essas etapas atuam em um jogo que adapta sua dificuldade de acordo com o desempenho do jogador, buscando mantê-lo mais entretido. A primeira etapa é a entrada de dados do usuário. Nesta etapa, as informações sobre o usuário são coletadas de uma base de dados onde é salvo seu progresso e as demais informações relacionadas ao jogo. Na etapa seguinte, a RNA é configurada, carregando os valores dos nós treinados que serão usados durante o jogo. A terceira etapa consiste na escolha da lição que se deseja aprender. Na quarta etapa o aluno joga, explorando e criando a melhor estratégia para vencer o jogo. Na última etapa, o aluno recebe um feedback do seu desempenho em forma de nota ou alguma recompensa dentro do jogo. O fluxograma na Figura 1 descreve uma visão geral da metodologia desenvolvida. 
VI Congresso Brasileiro de Informática na Educação (CBIE 2017)

Anais do XXVIII Simpósio Brasileiro de Informática na Educação (SBIE 2017)

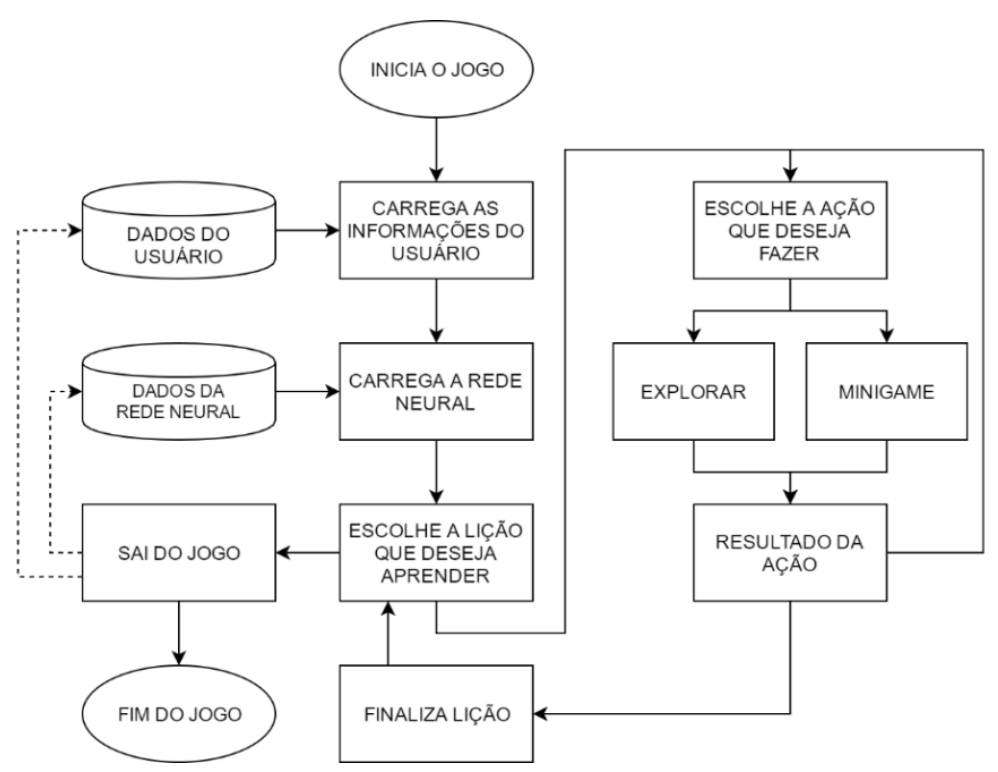

Figura 1. Fluxograma com as etapas até o término da sessão do jogo.

\subsection{Carga das Informações do Usuário}

Ao carregar informações relevantes ao ensino, como pontuações, status, percentual de progresso das atividades, lições completadas, entre outras. Caso seja a primeira sessão do usuário, as pontuações e demais informações de progresso são zeradas por padrão.

\subsection{Configuração da RNA}

Após carregar os valores, o jogo cria a instância da rede que será usada no decorrer do jogo. Para melhor validação, a rede foi treinada utilizando uma versão do jogo capaz de coletar informações específicas dos usuários. Esta versão foi disponibilizada para seis usuários com diferentes familiaridades com jogos, medido a partir da quantidade de horas jogadas por semana. Os valores obtidos são carregados inicialmente nos nós da rede.

\subsection{Estrutura da rede}

A Figura 2 mostra a estrutura da rede neural artificial usada na adaptação da dificuldade de acordo com a habilidade do jogador. A estrutura padrão de uma rede neural apresenta três componentes: camada de entrada, camada escondida e camada de saída. Cada camada possui um número fixo de nós. Posto isso, o número de nós das camadas de entrada e saída depende da aplicação da rede. A camada escondida, porém, não possui um número definido de nós. Não obstante, este número de nós afeta o desenvolvimento da rede. Como regra prática para a maioria dos problemas, define-se o número de nós na camada escondida como sendo a média entre os números na de entrada e na de saída. 
VI Congresso Brasileiro de Informática na Educação (CBIE 2017)

Anais do XXVIII Simpósio Brasileiro de Informática na Educação (SBIE 2017)

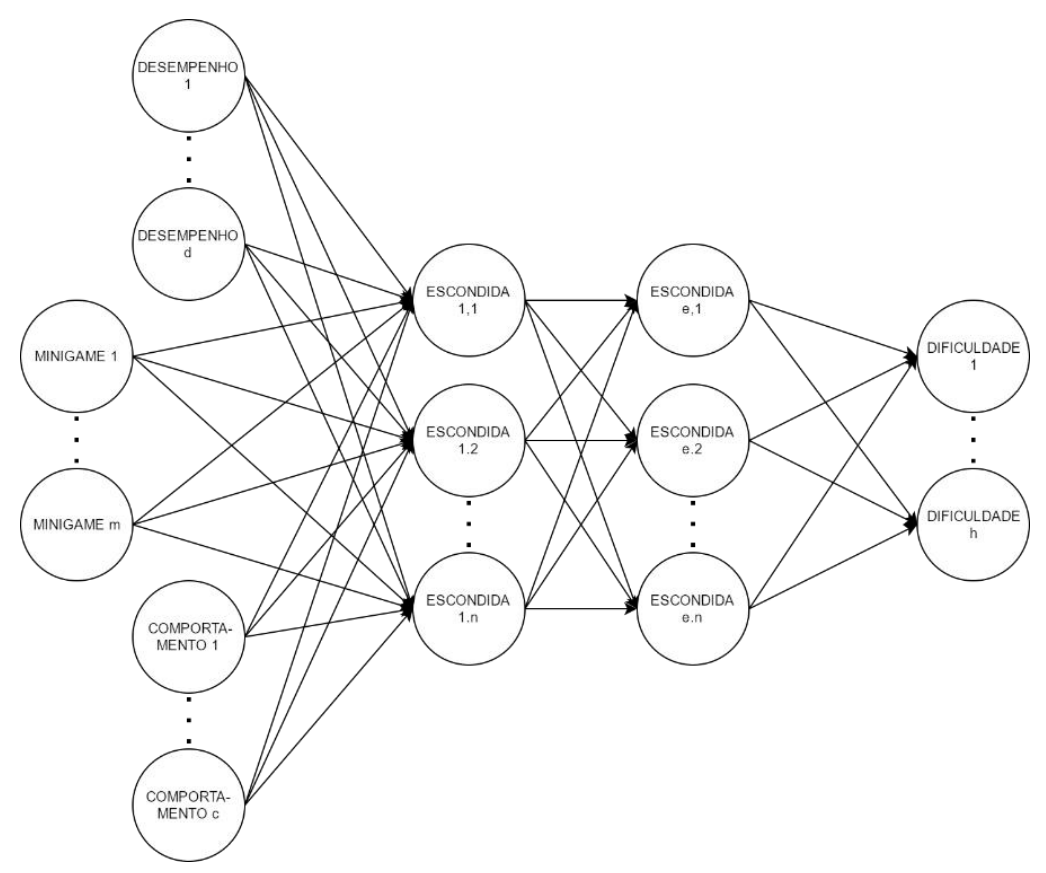

Figura 2. Estrutura da rede neural utilizada.

Para a identificação do nível de habilidade do aluno, faz-se necessária a análise a partir de, ao menos, três abordagens diferentes como entrada para a rede. A primeira está relacionada ao desempenho do aluno no jogo, que diferencia aquele que busca a melhor estratégia para alcançar o objetivo do jogo daqueles que jogam mais para se distrair ou se divertir. A segunda abordagem se refere à pontuação nos minigames dentro do jogo. Um aluno pode se sair bem nos minigames, mas ter um desempenho ruim no jogo, assim como o contrário também é possível. O número de nós é proporcional ao número de minigames. A última abordagem é relacionada ao comportamento do usuário dentro do jogo ou ao uso do celular. Esses nós podem analisar o comportamento exploratório do aluno dentro do jogo ou quanto tempo ele passa jogando durante as sessões.

No problema abordado, definiram-se os números sete e cinco para os nós de entrada e saída, respectivamente. Outrossim, determinou-se o número de seis nós para as duas camadas escondidas. No jogo, há quatro minigames. Um nó reunindo as três últimas pontuações para cada, garante que o aluno não será afetado pelo seu desempenho inicial, momento em que estará aprendendo as regras do jogo, nem por valores esdrúxulos devido à aleatoriedade de alguns minigames. O próximo nó na camada de entrada representa o desempenho do jogador na lição, e serve para ajustar a dificuldade do jogo em si, e não somente dos minigames. Os últimos dois nós são responsáveis por analisar o caráter exploratório do aluno. Os cinco nós na camada de saída representam cinco níveis de habilidade diferentes do jogador. Começando pelo nível um, que indica que o jogador não possui muita experiência com jogos e não apresenta um bom desempenho nos minigames e 
VI Congresso Brasileiro de Informática na Educação (CBIE 2017)

Anais do XXVIII Simpósio Brasileiro de Informática na Educação (SBIE 2017)

no desenvolvimento do jogo em si; até o nível cinco, alcançado pelo jogador mais experiente, que consegue uma boa pontuação em todos os minigames e no jogo. Para cada nível de habilidade, ocorrem diferentes níveis de adaptação, alterando-se, por exemplo, a dificuldade dos minigames ou o peso das ações executadas durante o jogo, visando a não frustrar o jogador e, ao mesmo tempo, não deixar o jogo entediante.

Segundo Hunicke (2005), as adaptações devem ser realizadas sem interromper ou atrapalhar a experiência principal do jogo, e estes ajustes se iniciam pela aplicação da entrada na rede neural. Para evitar que os ajustes sejam percebidos pelo usuário, cada nova adaptação do jogo é realizada durante a ação de "Dormir". Esta ação deve ser executada pelo menos uma vez por dia no jogo. Durante a ação, uma pequena animação é passada na tela do jogo enquanto a adaptação é feita ao fundo.

\subsection{Escolha da Lição}

Após todos os valores iniciais serem carregados, o jogo mostra um menu onde o jogador é capaz de selecionar a lição que deseja aprender. Para organizar a ordem do conteúdo ensinado e dar a sensação de evolução ao personagem, é possível limitar a escolha somente se o aluno completar a lição anterior. Esta estratégia também garante que o jogador preencherá os prérequisitos necessários para as lições mais avançadas. Dentro de cada lição, o jogo segue os padrões de designer de jogos educacionais definidos por Kelle et al. (2011) adaptados ao modelo ARCS [Keller 1987].

\subsection{Escolha da Ação}

Criado por John Keller (1987), o modelo ARCS de motivação é baseado na ideia de que existem quatro elementos principais no processo de aprendizagem capazes de motivar o estudante. O acrônimo destes quatro elementos compõe o nome do modelo: Atenção, Relevância, Confiança e Satisfação.

Para conseguir completar seu objetivo, o jogador deve escolher as ações que irá adotar durante a lição. Cada ação leva o personagem mais próximo do objetivo e influencia no status do personagem e.g. felicidade, social, cansaço físico, cansaço mental. Estas ações e seus efeitos servem para estimular a atenção do jogador, primeiro elemento do modelo ARCS. Os minigames cumprem o papel do segundo elemento do modelo. O jogo deve possuir minigames que se relacionem ao conteúdo, criando uma imagem do material ensinado em uma situação real ou fictícia. No jogo desenvolvido, a performance do jogador nos minigames também pode determinar a eficiência dos estudos, gerando um benefício claro da aplicação do conteúdo na vida do estudante. Porém, a habilidade do jogador não é o único fator que determina o progresso. O status, assim como as ações tomadas durante o jogo, devem claramente influenciar no objetivo final em forma de recompensas dentro do jogo. Esta característica, somado à adaptação de dificuldade fornecida pela rede, compõem os últimos dois elementos do modelo ARCS. Ao terminar uma ação, o jogador pode escolher 
VI Congresso Brasileiro de Informática na Educação (CBIE 2017)

Anais do XXVIII Simpósio Brasileiro de Informática na Educação (SBIE 2017)

entre salvar seu progresso e sair ou executar uma nova ação. Ao terminar a lição, o estudante recebe uma avaliação geral, baseada nas ações que tomou durante o jogo.

\section{Desenvolvimento}

\subsection{Design do jogo}

Kelle et al. (2011) identificou dois problemas comuns em jogos educacionais. O primeiro se refere ao design destes jogos, que muitas vezes tende a ser complexo e custoso. O segundo diz respeito à jogabilidade. $\mathrm{O}$ artigo descreve o processo de tradução das funções de aprendizagem para aspectos no jogo. Shuell e Moran (1996) listaram estas funções que se referem à atividades cognitivas e metacognitivas que devem ser provocadas para melhorar a eficiência do aprendizado. Kelle e colaboradores fizeram uma análise de acordo com a semântica do conceito pedagógico de cada uma. Em seguida, determina qual padrão de design de jogo é o mais adequado para dar suporte ao conceito. Para averiguar as relações estabelecidas, os padrões foram explicados para um grupo de especialistas.

Para a aplicação desenvolvida, foram definidos padrões dentro do conteúdo do jogo que se relacionam com os identificados no estudo. Cada padrão fornecido por Kelle e seus colaboradores foi estudado e implementado durante o desenvolvimento do jogo. Cada um exerce pelo menos uma função de ensino e aprendizagem e busca melhorar o ensino do conteúdo do jogo. Os status do personagem, pontuação e limite de tempo nos minigames, bônus, elementos interativos no cenário são alguns exemplos de padrões adotados no jogo.

\subsection{Características do jogo}

O jogo foi desenvolvido para celulares Android 4.1 ou superior usando a engine Unity 2D. Este tem o intuito de ensinar técnicas e hábitos de estudo ao aluno. O objetivo do jogo é completar o estudo de todas as lições semanais, para que na sexta-feira o personagem consiga se sair bem em sua prova. Durante o jogo, o aluno deve escolher as melhores ações que conseguir estudar todo o conteúdo da prova, recebendo bonificações caso adote bons hábitos de estudo. A ação "Estudar" é a única que afeta diretamente o progresso do estudo do personagem, e as microssessões de estudos são representadas por minigames dentro do jogo. Assim, o aluno deverá aprender os hábitos, costumes e técnicas que podem ajudá-lo a aprender um determinado assunto. A lição termina quando o personagem faz a prova, e o resultado desta prova é usado também para a avaliar o progresso do aluno na lição.

\subsubsection{Minigames}

No jogo há quatro minigames diferentes por lição. O aluno deverá jogar um minigame ao executar a ação de estudar. Eles foram projetados para fornecer um desafio diferente ao jogador, além do jogo em si, mantendo-se curtos e divertidos, e exigindo normalmente raciocínio rápido e concentração. Os minigames não necessariamente buscam ensinar o conteúdo do jogo, mas servem como um exercício mental que estimula e motiva o aluno. 
VI Congresso Brasileiro de Informática na Educação (CBIE 2017)

Anais do XXVIII Simpósio Brasileiro de Informática na Educação (SBIE 2017)

\subsubsection{Exploração}

O jogo consiste em cliques nas ações que o personagem irá executar, tais como estudar, dormir, comer, correr, conversar e outras. $\mathrm{O}$ aluno deve escolher as ações para ter o melhor desempenho nos estudos e alcançar o objetivo do jogo. Cada ação possui um efeito sobre o status do personagem definidas para possibilitar diferentes estratégias, podendo ser positivo ou negativo. No jogo, estes também influenciam na eficiência do estudo.

\subsubsection{Recompensa}

Os bônus são apresentados ao fim de cada sessão de estudo. Estes bônus ajudam o aluno a conseguir mais pontos para finalizar as tarefas mais rapidamente, e fazem parte do conteúdo de ensino do jogo, embora não sejam ensinados diretamente. Este aspecto do jogo contribui para incentivar o caráter exploratório no aluno, incitando-o a buscar pelo jogo ações que podem lhe atribuir bônus. Tais recompensas podem ser obtidas por conta do ambiente de estudo, higiene, estado físico, distrações ou outros fatores que podem afetar o estudo.

\section{Aplicação Experimental}

Para a validação da hipótese apresentada, fez-se necessária uma prova de conceito com sujeitos de Engenharia da Computação. Foram escolhidos 20 alunos do curso - pela disponibilidade, por possuírem vários aparelhos Android e pelos diferentes graus de habilidade identificados pelos próprios alunos. As habilidades foram julgadas com base na frequência com que jogam no celular e pela pontuação em jogos comuns entre eles.

O jogo desenvolvido foi instalado nos aparelhos dos alunos. Pediu-se que jogassem o jogo até finalizarem a primeira lição. Após o término da lição, requisitou-se que os sujeitos respondessem um questionário sobre o jogo e as ferramentas utilizadas. O questionário possui 8 perguntas e deve ser respondido seguindo a numeração de 1 a 5 , em que 1 corresponde a "Discordo Totalmente" e 5 a "Concordo Totalmente". O questionário não exigia o nome ou qualquer identificação, para assegurar o anonimato.

Tabela 1. Perguntas realizadas e mediana das respostas correspondentes.

\begin{tabular}{|l|c|}
\hline Perguntas & Mediana \\
\hline Você achou o jogo divertido? & 4 \\
\hline Você achou o jogo desafiador? & 4 \\
\hline Você se sentiu motivado a continuar jogando? & 4 \\
\hline $\begin{array}{l}\text { A maneira como o conteúdo é apresentado lhe motivou a continuar } \\
\text { jogando? }\end{array}$ & 3 \\
\hline Você achou o jogo repetitivo? & 2 \\
\hline Você achou os minigames muito fáceis (1)/difíceis (5)? & \\
\hline
\end{tabular}


VI Congresso Brasileiro de Informática na Educação (CBIE 2017)

Anais do XXVIII Simpósio Brasileiro de Informática na Educação (SBIE 2017)

\begin{tabular}{|l|c|}
\hline Você achou o assunto interessante? & 5 \\
\hline Você aprendeu novas informações relacionadas ao assunto abordado? & 4 \\
\hline
\end{tabular}

Com esses resultados, observou-se que os alunos, de maneira geral, ficaram satisfeitos com a adaptação e com o conteúdo ensinado. Eles acharam o jogo divertido e não desafiador. $\mathrm{O}$ desenvolvimento do jogo segundo os padrões de design também contribuiu para a motivação dos alunos. Alguns acharam o jogo repetitivo e isso pode ser um fator negativo para manter o usuário entretido. Graças à adaptação, os alunos não acharam o nível nem muito difícil nem muito fácil. Com uma mediana igual a 4.0, estes se sentiram motivados a aprender o conteúdo e aplicá-lo no seu dia-a-dia.

Todos os alunos iniciam o jogo em uma dificuldade intermediária, e a medida que avançam, suas performances fornecem dados para a adaptação do jogo. Como esperado, foi observado que aqueles com pouca experiência em jogos tendem a ter uma pontuação menor nos minigames comparado com os que tem mais experiência. Nestes casos, o jogo se adaptou para uma dificuldade mais fácil para evitar que os alunos se frustrassem com o jogo. Outra característica analisada para a adaptação foram as ações relacionadas à exploração do conteúdo. Aqueles mais curiosos exploram os recursos, navegando entre os ambientes, escolhendo diferentes atividades e determinando o melhor curso para atingir o objetivo final. Por outro lado, outros escolheram um caminho mais objetivo, focando nas ações que afetariam diretamente no progresso sem explorar o jogo. Este último caso pode ser prejudicial para o aluno visto que ao finalizar a lição não terá contemplado todo o conteúdo a ser ensinado. Por esta razão, o jogo analisou o comportamento exploratório do aluno e adaptou a jogabilidade de maneira a incentivar ações diferentes, seja com bonificações ou dicas.

\section{Conclusão e trabalho futuros}

Na execução do trabalho apresentado, criou-se um método capaz de identificar e adaptar a dificuldade de um jogo baseada nas habilidades do jogador. O processo é realizado sem interferir na jogabilidade do mesmo, ocorrendo sem o conhecimento do aluno. O método foi testado em um jogo educacional móvel moldado por uma arquitetura fundamentada em teorias de motivação, que sugerem manter o aluno interessado no jogo e motivado a aprender.

Com o objetivo de validar o ganho de aprendizagem com o uso da técnica de adaptação, faz-se necessária a criação de um pré/pós-teste do assunto abordado. Com isso, será possível analisar a eficiência da adaptação em termos de conhecimento do aluno. Além disso, espera-se que, com o avanço da tecnologia, seja possível incluir diferentes aspectos do jogador, de maneira que o jogo se comporte como um tutor pessoal, analisando o processo de aprendizado do aluno e guiando-o à melhor estratégia de ensino. As técnicas de aprendizagem de máquina serão vitais para este processo, coletando e analisando dados comportamentais a tal ponto que o jogo se torne único para cada jogador. 
VI Congresso Brasileiro de Informática na Educação (CBIE 2017)

Anais do XXVIII Simpósio Brasileiro de Informática na Educação (SBIE 2017)

\section{Referências}

Baker, R. S., D'Mello, S. K., Rodrigo, M. M. T. and Graesser, A. C. (2010). Better to be frustrated than bored: The incidence, persistence, and impact of learners' cognitiveaffective states during interactions with three different computer-based learning environments. International Journal of Human-Computer Studies, 68(4), 223-241.

Bouvier, P., Sehaba, K. and Lavoué, É. (2014). A trace-based approach to identifying users' engagement and qualifying their engaged-behaviours in interactive systems: application to a social game. User Modeling and User-Adapted Interaction, 24(5), 413-451.

Chun, Y., Youm, K. and Oh, K. (2015). Difficulty Balancing and Review Management System for Smart Mobile Learning. International Journal of Multimedia and Ubiquitous Engineering, 10(1), 219-226.

Erhel, S. and Jamet, E. (2013). Digital game-based learning: Impact of instructions and feedback on motivation and learning effectiveness. Computers \& Education, 67, 156-167.

Hunicke, R. (2005). The case for dynamic difficulty adjustment in games. In Proceedings of the 2005 ACM SIGCHI International Conference on Advances in computer entertainment technology (pp. 429-433). ACM.

Jovanovic, M., Starcevic, D., Minovic, M. and Stavljanin, V. (2011). Motivation and multimodal interaction in model-driven educational game design. IEEE Transactions on Systems, Man, and Cybernetics-Part A: Systems and Humans, 41(4), 817-824.

Ke, F. and Grabowski, B. (2007). Gameplaying for maths learning: cooperative or not?. British Journal of Educational Technology, 38(2), 249-259.

Kelle, S., Klemke, R. and Specht, M. (2011). Design patterns for learning games. International Journal of Technology Enhanced Learning, 3(6), 555-569.

Keller, J. M. (1987). Development and use of the ARCS model of instructional design. Journal of Instructional Development, 10(3), 2-10.

Kim, B., Park, H. and Baek, Y. (2009). Not just fun, but serious strategies: Using metacognitive strategies in game-based learning. Computers \& Education, 52(4), 800-810.

Peirce, N., Conlan, O. and Wade, V. (2008). Adaptive educational games: Providing noninvasive personalised learning experiences. In Digital Games and Intelligent Toys Based Education, 2008 Second IEEE International Conference on (pp. 28-35). IEEE.

Pogacnik, M., Guna, J., Papic, M. and Bester, J. (2009). Quest For Knowledge-A mobile learning platform. In EUROCON 2009, EUROCON'09. IEEE (pp. 1305-1308). IEEE.

Shuell, T.J. and Moran, K.A. (1994) 'Learning theories: historical overview and trends', in T. Husen and T.N. Postlethwaite (Eds.): The International Encyclopedia of Education, 2nd ed., pp.3340-3345, Pergamon, Oxford, UK.

Susi, T., Johannesson, M. and Backlund, P. (2007). Serious games: An overview. Technical Report HS- IKI -TR-07-001, School of Humanities and Informatics, University of Skövde, Sweden. 